\title{
$\mathrm{PH} 103$ acualitad
}

\section{EI IAPH difunde una guía metodológica para la redacción de proyectos de conservación en bienes muebles}

\author{
El Instituto Andaluz del Patrimonio Histórico, con el consenso de la Consejería de Cultura y Patrimonio \\ Histórico (CCPH), elabora una guía que permite el correcto desarrollo de los contenidos de los proyectos \\ de conservación de un modo normalizado, con la finalidad de proporcionar a los especialistas en \\ conservación y restauración de bienes muebles un protocolo para su redacción, así como facilitar su \\ seguimiento y evaluación. El relevante documento está disponible en el repositorio del IAPH en el siguiente \\ enlace: https://repositorio.iaph.es/handle/11532/336472
}

Araceli Montero Moreno | Tratamiento en Bienes Muebles, Instituto Andaluz del Patrimonio Histórico

URL de la contribución <http://www.iaph.es/revistaph/index.php/revistaph/article/view/4893>

El documento Guía metodológica para la redacción de proyectos de conservación en bienes muebles nace con la intención de protocolizar el contenido de los proyectos de conservación para proporcionar a los especialistas en conservación y restauración un apoyo práctico para su redacción, así como facilitar su seguimiento y la evaluación de los mismos por parte de la propia Administración.

El proyecto de conservación es un documento de obligado cumplimiento, según establece la Ley 14/2007, de 26 de noviembre, de Patrimonio Histórico de Andalucía, cuando se vayan a realizar actuaciones de conservación, restauración o rehabilitación en bienes muebles o inmuebles inscritos en el Catálogo General del Patrimonio Histórico Andaluz. Se trata de un documento técnico donde se justifican, describen y planifican todas las acciones que se van a desarrollar sobre el bien cultural.

El proyecto de conservación se regula en el artículo 22.1 de esta ley, que deberá ajustarse al contenido que reglamentariamente se determine, "incluyendo como mínimo, el estudio del bien y sus valores culturales, la diagnosis de su estado, la descripción de la metodología a utilizar, la propuesta de actuación desde el punto de vista teórico, técnico y económico y la incidencia sobre los valores protegidos, así como un programa de mantenimiento" (LPHA).
El IAPH, en sus 30 años de trayectoria, entiende la intervención en patrimonio como un proceso crítico, basado en un conocimiento interdisciplinar y riguroso del bien, donde se asumen los objetivos y criterios definidos en los documentos y textos internacionales que constituyen el corpus disciplinar del patrimonio. Desde la regulación del proyecto de conservación por la Ley 14/2007, el IAPH ha sido consciente de su importancia, considerándolo como el instrumento documental que permite ordenar y recoger los resultados de su metodología de trabajo. Ante la inexistencia de un reglamento que desarrollase los contenidos del proyecto, así como la ausencia de instrucciones que los orientasen en la variada casuística existente, el IAPH planteó en 2012 diseñar una hoja de ruta para actualizar el vigente marco conceptual andaluz de la conservación del patrimonio histórico, donde se insertaba la

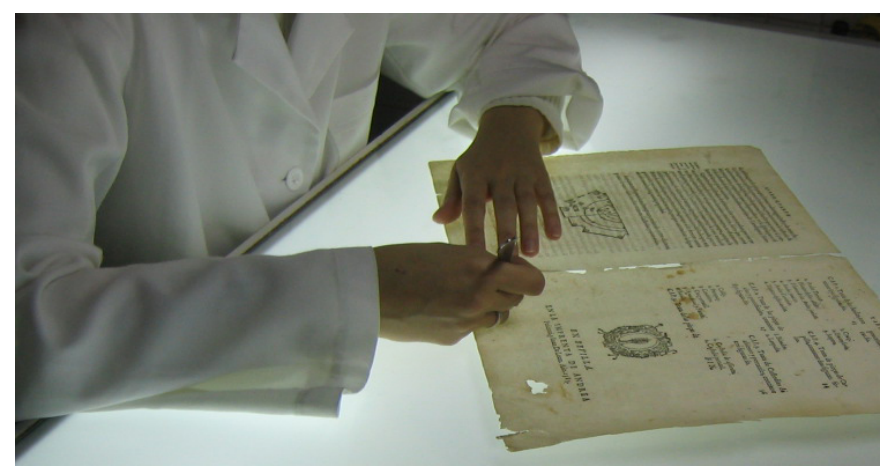

Taller del papel del IAPH | foto Fondo Gráfico IAPH 


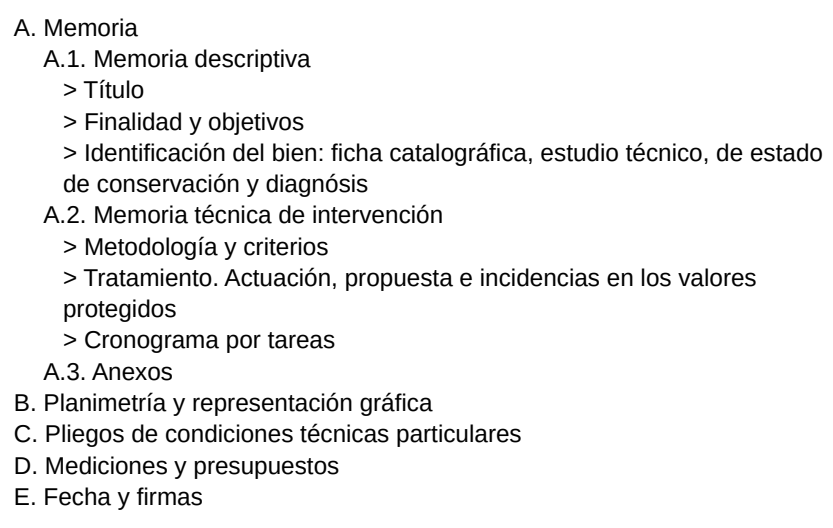

elaboración de una guía metodológica para la redacción de proyectos de conservación en bienes muebles, como parte de sus acciones de normalización para la conservación patrimonial, que pudiera ser exportable a cualquier contexto de tratamiento del patrimonio mueble.

Con el objetivo de una renovación metodológica que diese cumplimiento a las acciones de tutela de carácter general, se acometió la elaboración de un documento que permitiese protocolizar los procedimientos y procesos contenidos en el proyecto de conservación, en términos de eficiencia y la calidad de las intervenciones, siendo ésta la génesis de esta guía.

El contenido de la misma es el resultado de este modelo de normalización, donde se plasma un método de carácter científico que ha sido experimentado, demostrando a lo largo de los años sus buenos resultados en los proyectos diseñados por el IAPH ${ }^{1}$. Su planteamiento y contenido ha estado debatido con un equipo técnico de la Consejería de Cultura y Patrimonio Histórico (CCPH), como competente en materia de patrimonio, expresamente constituido para este fin, que ha trabajado en estrecha colaboración durante la etapa final de la redacción del documento, hasta su consenso final que culminó en marzo de 2020.

Desde la Dirección General de Patrimonio Histórico y Documental de la CCPH se transmitió el interés por la publicación y difusión de este documento, argumentando que podría llegar a ser un texto orientativo de referencia tanto para los profesionales que elaboran los proyectos de conservación, así como para la propia Administración, que ha de pronunciarse sobre aquellos que recibe mediante comunicación o solicitud de autorización, velando por tanto por la calidad de las actuaciones sobre los bienes protegidos atendiendo a lo requerido en los artículos 43.2. y 43.3. de la LPHA.

La guía responde a los contenidos propios del proyecto de conservación, tomando como punto de partida los supuestos de la Ley, que dan como resultado la estructura básica que indica el cuadro adjunto.

Esta guía pretende establecer un modelo de organización de los documentos del proyecto de conservación, donde se detallen y especifiquen cuáles deben ser el contenido de los mismos, que sea apto para las diferentes acciones de intervención en términos de eficacia, calidad, participación y economía. Aunque ciertamente no se trate de un texto legal ni pretende dar respuesta a todas las dudas que se puedan plantear en la ley, su publicación supone una aportación innovadora para el desarrollo de los proyectos de conservación, hasta ahora no realizada, de acuerdo a un proceso normalizado que sirva para cubrir el amplio espectro de los bienes culturales. La difusión del documento mediante el repositorio del IAPH permite el acceso a todos los profesionales relacionados con la redacción de proyectos de conservación, tanto de la comunidad autónoma andaluza como fuera de ella, así como al público general interesado por algún aspecto constitutivo de los mismos, debido a la garantía de acceso abierto que ofrece este medio.

\section{NOTAS}

1. Recomendamos la lectura del artículo "Avanzando.

El IAPH ante el reto de la conservación. Una trayectoria marcada por la actualización metodológica desde la reflexión y la acción" (en revista $P H, n .^{\circ} 100$, sección especial 30 años). Disponible en: https://www.iaph.es/ revistaph/index.php/revistaph/article/view/4697 [Consulta: 17/05/2021]. 